\section{(6) OPEN ACCESS} Performance Research Centre, ASPETAR, Qatar Orthopaedic and Sports Medicine Hospital

\section{Correspondence to}

Dr Julien Périard, AspetarQatar Orthopaedic and Sports Medicine Hospital, Research and Education Centre, PO Box 29222, Doha, Qatar; julien.periard@aspetar.com

Received 31 October 2013 Revised 17 January 2014 Accepted 19 January 2014

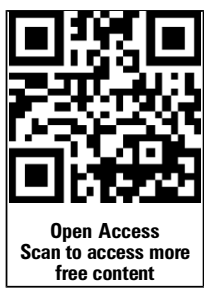

\title{
Coping with heat stress during match-play tennis: Does an individualised hydration regimen enhance performance and recovery?
}

\author{
Julien D Périard, Sebastien Racinais, Wade L Knez, Christopher P Herrera, \\ Ryan J Christian, Olivier Girard
}

\begin{abstract}
Objectives To determine whether an individualised hydration regimen reduces thermal, physiological and perceptual strain during match-play tennis in the heat, and minimises alterations in neuromuscular function and physical performance postmatch and into recovery. Methods 10 men undertook two matches for an effective playing time (ball in play) of $20 \mathrm{~min}$ ( 113 min) in $\sim 37^{\circ} \mathrm{C}$ and $\sim 33 \% \mathrm{RH}$ conditions. Participants consumed fluids ad libitum during the first match (HOT) and followed a hydration regimen (HYD) in the second match based on undertaking play euhydrated, standardising sodium intake and minimising body mass losses.
\end{abstract}

Results HYD improved prematch urine specific gravity $(1.013 \pm 0.006$ vs $1.021 \pm 0.009 \mathrm{~g} / \mathrm{mL} ; p<0.05)$. Body mass losses $(\sim 0.3 \%)$, fluid intake $(\sim 2 \mathrm{~L} / \mathrm{h})$ and sweat rates $(\sim 1.6 \mathrm{~L} / \mathrm{h})$ were similar between conditions. Core temperature was higher during the first 10 min of effective play in HOT $(p<0.05)$, but increased similarly $\left(\sim 39.3^{\circ} \mathrm{C}\right)$ on match completion. Heart rate was higher $(\sim 11 \mathrm{bpm})$ throughout HOT $(p<0.001)$. Thermal sensation was higher during the first $7.5 \mathrm{~min}$ of effective play in HOT $(p<0.05)$. Postmatch knee extensor and plantar flexor strength losses, along with reductions in $15 \mathrm{~m}$ sprint time and repeated-sprint ability $(p<0.05)$, were similar in both conditions, and were restored within $24 \mathrm{~h}$.

Conclusions Both the hydration regimen and ad libitum fluid consumption allowed for minimal body mass losses $(<1 \%)$. However, undertaking match-play in a euhydrated state attenuated thermal, physiological and perceptual strain. Maximal voluntary strength in the lower limbs and repeated-sprint ability deteriorated similarly in both conditions, but were restored within $24 \mathrm{~h}$.

\section{INTRODUCTION}

Tennis is a multifactorial sport requiring a combination of specific physical attributes such as speed, agility, power, muscular and aerobic endurance, as well as the mental capacity to anticipate, react and make split-second decisions. ${ }^{1}$ During prolonged (1-3 h) match-play under heat stress $\left(>35^{\circ} \mathrm{C}\right)$, these attributes may be compromised relative to when play is undertaken in cool $\left(15-25^{\circ} \mathrm{C}\right)$ conditions, due to the development of thermal strain (ie, a rise in core and skin temperature). Indeed, physiological (eg, heart rate) and perceptual (eg, perceived exertion and thermal comfort) responses are exacerbated during match-play in the heat, as are strength losses in the lower limbs (eg, maximal isometric torque). ${ }^{2}$ The rise in thermal strain has also been suggested to lead to autonomic and behavioural thermoregulatory responses, whereby point duration decreases or time between points increases, in order to reduce effective playing time and overall metabolic heat load. ${ }^{34}$

Typically, a rise in thermal strain during exercise in the heat is accompanied by progressive dehydration if fluids are not sufficiently consumed, ${ }^{5-8}$ which is known to exacerbate the development of hyperthermia and impair prolonged exercise performance. ${ }^{4} 910$ During match-play tennis, sweat rates vary based on ambient temperature and humidity, but can reach $2.5 \mathrm{~L} / \mathrm{h}$ in certain individuals. $^{11}{ }^{12}$ It has been suggested that drinking to thirst in ecologically valid settings (eg, outdoor cycling time trial) allows athletes to compensate for these sweat rates and meet their fluid needs. ${ }^{13} 14$ However, the sensation of thirst may often not be perceived until $1.5 \mathrm{~L}$ of body water is lost, ${ }^{15} 16$ or a $2 \%$ body mass deficit is incurred. ${ }^{17}$ As such, ad libitum fluid consumption may lead to involuntary dehydration. $^{11}$ It has, therefore, been recommended that hydration regimens be individualised based on sweat rate, as well as composition (eg, sodium: $\left.\mathrm{Na}^{+}\right) .{ }^{1}$ However, gastric emptying is only $\sim 1.2 \mathrm{~L} / \mathrm{h},{ }^{18}$ which may prevent some hydration regimens to fully offset fluid losses when sweating is profuse. Thus, it is further recommended to replace fluid losses to avoid dehydration $>2 \%$ of pre-exercise body mass during prolonged exercise. ${ }^{5}$ It is also suggested that fluid consumption should not result in a gain of body mass; however, this latter point may be irrelevant if an individual begins exercise in a severely hypohydrated state, ${ }^{8}$ which is characteristic in tennis players. ${ }^{19} \quad 20$ Interestingly, the regular breaks during match-play tennis allow ample opportunity to rehydrate. Despite these opportunities, it is unclear whether hydration state at the onset of and during matchplay tennis in the heat influences performance and perception.

Therefore, the aim of this study was to determine whether an individualised hydration regimen reduces thermal, physiological and perceptual responses during match-play tennis in the heat, compared with the typical hydration habits of highlevel players. A further aim was to determine whether implementing a hydration regimen would attenuate the level of impairment in neuromuscular function and physical performance characteristics when competing in the heat and accelerate the recovery process $(24-48 \mathrm{~h})$. It was hypothesised 
that implementing a hydration regimen based on undertaking play in a euhydrated state, minimising body mass losses and standardising $\mathrm{Na}^{+}$intake during play, would prevent dehydration and attenuate the elevation in core body temperature and its concomitant deleterious influence on performance and perception.

\section{METHODS}

\section{Subjects}

Ten male tennis players (International Tennis Federation number 1-3), unacclimatised to heat, were recruited to participate in the study. The participants' mean age, height, body mass and years of match-play tennis experience were $23 \pm 5$ years, $182 \pm 7.3 \mathrm{~cm}$, $79 \pm 7.8 \mathrm{~kg}$ and $17 \pm 4$ years. The participants played an average of $17 \pm 11$ tournaments and $60 \pm 22$ matches/year. Their weekly training volume was $12 \pm 6 \mathrm{~h}$. The participants were informed of the study aims, requirements and risks before providing their written informed consent.

\section{Study design}

Participants played two simulated matches on hard-court surfaces separated by $72 \mathrm{~h}$ ( $\mathrm{n}=4$ pairs) or $144 \mathrm{~h}(\mathrm{n}=1$ pair). They were paired according to their level of play and competed against the same opponent in both matches. Both matches were played outdoors in hot conditions. In the first match (HOT: $36.8 \pm 0.3^{\circ} \mathrm{C}, 33.3 \pm 3.8 \%$ relative humidity, $34.2 \pm 0.4^{\circ} \mathrm{C}$ wet bulb globe temperature (WBGT)), players were instructed to eat and drink as they normally would. In the second match (HYD: $36.9 \pm 2.3^{\circ} \mathrm{C}, \quad 32.5 \pm 12.8 \%$ relative humidity, $35.2 \pm 2.4^{\circ} \mathrm{C}$ WBGT), they were given a hydration regimen to follow (see Hydration section). The matches consisted of $20 \mathrm{~min}$ $(2 \times 10 \mathrm{~min})$ of effective playing time. To calculate the effective playing time, each rally duration was measured with a stopwatch from the start (ie, ball leaving the hand of the serving player) to the end of the rally (ie, ball into the net or called out) and summed until the total duration reached 10 and 20 min (midmatch and postmatch, respectively). First serve faults and double faults were not counted for point duration. As such, total match duration (HOT: 116.6 $\pm 8.1 \mathrm{~min}$ and HYD: 111.0 $\pm 23.2 \mathrm{~min}$ ) was of typical length for a three-set match. Data were analysed as a function of effective playing time to ensure that outcome measures were compared after an equivalent effective playing time (eg, $2.5 \mathrm{~min}$ ) in both conditions. Each 10 min of effective play was separated by $\sim 25 \mathrm{~min}$ to conduct body mass, blood lactate (see below) and physical performance measurements. ${ }^{21}$ One to 3 days prior to the start of the study, participants visited the testing and playing venue where they were thoroughly familiarised with the testing procedures and assessments.

\section{Experimental protocol}

On arrival on match days (9:00), participants provided a urine sample for the measurement of urine specific gravity (USG; Pal-10-S, Vitech Scientific Ltd, West Sussex, UK) and inserted a telemetric temperature pill in the rectum for measuring core temperature. After being instrumented, participants performed a standardised warm-up of running at $9 \mathrm{~km} / \mathrm{h}$ for $5 \mathrm{~min}$ on the indoor court $\left(\sim 22^{\circ} \mathrm{C}\right)$. This was followed by the pre-exercise baseline neuromuscular function (see Neuromuscular function section) and physical performance assessments (see Physical performance section). These assessments were also performed postmatch, and 24 and $48 \mathrm{~h}$ after match completion. On match days, participants were then moved outdoors and performed a $10 \mathrm{~min}$ tennis-specific warm-up (rallies and serves). Body mass
(Seca 769, Hamburg, Germany) and perceptual measures were recorded, along with blood lactate from a finger (Lactate Pro, Arkray Global Business Inc, Kyoto, Japan). These were also measured postmatch. Prior to starting the match, an absorbent pad with protective dressing (Tegaderm + Pad, $3 \mathrm{M}$ Health Care, Borken, Germany) was placed at the level of the right scapula (after cleaning the skin with deionised water) to determine sweat sodium concentration (Dimension Xpand Plus, Siemens, Munich, Germany). On the days when participants did not play, they followed a standardised training programme led by a tennis coach $(\sim 60 \mathrm{~min})$ on the outdoor court after completing the assessments.

\section{Hydration}

Prior to the HOT match, participants were instructed to eat and drink as they normally would during tournament play. During the match they consumed water and a commercially available sport drink (Gatorade, Chicago, Illinois, USA) ad libitum. They were also provided with bananas and granola bars (Nature Valley, General Mills, Minneapolis, Minnesota, USA). A researcher recorded the amount and type of foods and fluids consumed during play. In addition, all participants kept a food diary to record the amount of food consumed at each meal, which were prepared for them, in order to replicate their diet before the second match.

One day prior to the HYD match, participants were asked to consume a specific volume of water $(6 \mathrm{~mL} \mathrm{~kg} \mathrm{body} / \mathrm{mass})$ with target $\mathrm{Na}^{+}$content of $185 \mathrm{mg} / \mathrm{L}$ every $2.5 \mathrm{~h}$ ( $\sim 4-5$ times/day) to ensure euhydration at the start of play. During play they were provided with and required to drink a volume of fluids that matched $70 \%$ of their sweat loss from the HOT match. This target was selected to strike a balance between allowing participant to keep changes in body mass below 2\%, while considering gastrointestinal comfort and tolerance, as well as gastric emptying. The hydration regimen was based on sweat rate alone. A standardised $\mathrm{Na}^{+}$content of $860 \mathrm{mg} / \mathrm{L}$ was chosen to promote the optimal maintenance of plasma $\mathrm{Na}^{+}$levels and plasma volume during play, while not being too high as to negatively impact on palatability. ${ }^{22}$ The level of $\mathrm{Na}^{+}$was manipulated through the use of a commercially available carbohydrate-free electrolyte supplement (Nuun \& Company Inc, Seattle, Washington, USA) and sport drink (Gatorade). Although a specific volume of fluids was given to consume, participants were allowed to request more water. Additional water was supplemented accordingly to maintain the target $\mathrm{Na}^{+}$content. Carbohydrate intake was matched to the HOT trial by providing the same foods. Given that the regimen was based on having played one match in the heat, the HYD trial could not be randomised.

\section{Match-play, thermal, physiological and perceptual measurements}

The scoring and timing characteristics of the matches complied with the 2012 ITF Rules ${ }^{23}$ and are explained in a companion paper. $^{3}$ Total playing time, point duration, between-point duration and effective playing percentage were calculated for each match. Three new tennis balls were used for each $10 \mathrm{~min}$ of effective play, with the players retrieving balls between points. Core and quadriceps skin temperature (VitalSense, Mini Mitter, Respironics, Herrsching, Germany), heart rate (Polar Electro, Lake Success, New York, USA) and perceptual measures of thermal comfort ${ }^{24}$ (scales 1-7), thermal sensation ${ }^{25}$ (scales 1-7) and ratings of perceived exertion ${ }^{26}$ (RPE; scales 6-20) were recorded at $2.5 \mathrm{~min}$ intervals of effective playing time. Every 
effort was made to collect these measures between games so as not to disrupt the continuity of play.

\section{Neuromuscular function}

The protocol to evaluate maximal torque production (MP35 and BSL Pro V.3.6.7, Biopac Systems Inc, Santa Barbara, USA) was performed twice in a counter-balanced order, once to evaluate the knee extensors (KE) and once to evaluate the plantar flexors (PF). The neuromuscular assessment consisted of a $5 \mathrm{~s}$ maximal voluntary isometric contraction (MVC), on which a paired stimulus (doublet, $100 \mathrm{~Hz}$ ) was superimposed. The MVC was followed by one doublet and three single pulses. This sequence was repeated with a $30 \mathrm{~s}$ rest between repetitions and $5 \mathrm{~s}$ between stimulations. Stimulation and measurement procedures are described in Périard et al. ${ }^{2}$ Peak twitch torque was calculated from the mean of the six potentiated twitches. Voluntary activation (VA) was calculated with the interpolated twitch technique using the potentiated doublet as VA $(\%)=[1-$ (superimposed doublet/resting potentiated doublet) $] \times 100 .^{27}$

\section{Physical performance}

Sprints

Participants performed three $15 \mathrm{~m}$ sprints as fast as possible separated by $15 \mathrm{~s}$ alongside the outdoor tennis court. Three seconds prior to the beginning of each sprint, they were asked to assume the ready position and await the start signal. Sprint times were measured on crossing the finish line using two photocells connected to an electronic timer (Microgate SRL, Bolzano, Italy). The sprints were performed in a back and forth format to allow for passive recovery during the short rest period. Initial sprint time, total sprint times and the sprint decrement score were calculated. ${ }^{21}$

\section{Jumps}

Squat jumps starting from a static semisquatting position $\left(\sim 90^{\circ}\right.$ of flexion) maintained for $\sim 1 \mathrm{~s}$ and without any preliminary movement were performed, along with countermovement jumps starting from a standing position, squatting down and then extending the knees in one continuous movement. During all jump tests, the hands were kept on the hips to minimise the contribution of the upper limbs. An electronic timer was connected to an optical acquisition system (Optojump, Microgate SRL, Bolzano, Italy) for measuring flight times $\left(t_{f}\right)$. From the flight times, jump height was calculated. ${ }^{28}$ The better of two trials was recorded for each jump. However, in the event that a jump was clearly not maximal or a fault was committed, it did no count as one of the two official jumps to be compared and was repeated.

\section{Statistical analysis}

All statistical calculations were performed using PASW software V.21.0 (SPSS, Chicago, Illinois, USA). A repeated-measures ANOVA was performed to test significance between and within treatments. Outcome variables were tested using Mauchly's procedure for sphericity. Whenever the data violated the assumption of sphericity, $\mathrm{p}$ values and adjusted degrees of freedom based on Greenhouse-Geisser correction were reported instead. Where significant effects were established, pairwise differences were identified using the Bonferroni post hoc analysis procedure adjusted for multiple comparisons. Significant differences in hydration status were identified using Student's paired $t$ tests. A non-parametric Wilcoxon matched-pairs signed-rank test was used to test differences in match characteristics between HOT and HYD conditions. The significance level was set at $\mathrm{p}<0.05$. All values are expressed as means \pm SD.

\section{RESULTS}

\section{Hydration status}

The hydration regimen improved prematch USG: $1.013 \pm 0.006$ (HYD) vs $1.021 \pm 0.009 \mathrm{~g} / \mathrm{mL}$ (HOT; $\mathrm{p}<0.05)$. Body mass was higher throughout the HYD $(79.5 \pm 7.9$ and $79.7 \pm 8.2 \mathrm{~kg})$ condition compared with HOT $(78.8 \pm 7.8$ and $78.2 \pm 8.3 \mathrm{~kg}$ ) (prematch and postmatch, respectively; $\mathrm{p}<0.05$ ), but did not differ over time. Fluid intake during the match in HYD $(2.1 \pm 0.4 \mathrm{~L} / \mathrm{h})$ and HOT $(1.8 \pm 0.5 \mathrm{~L} / \mathrm{h})$ was similar, as were changes in body mass (HYD: $0.2 \pm 1.1$ vs HOT: $-0.7 \pm 1.3 \%$ ) and sweat rates (HYD: $1.5 \pm 0.3$ vs HOT: $1.6 \pm 0.4 \mathrm{~L} / \mathrm{h}$ ). Sweat $\left[\mathrm{Na}^{+}\right]$was lower after the HYD $(55.8 \pm 17.2 \mathrm{mmol} / \mathrm{L})$ match compared with HOT $(63.6 \pm 18.7 \mathrm{mmol} / \mathrm{L} ; \mathrm{p}<0.05)$, which led to a lower $\mathrm{Na}^{+}$ loss in the HYD relative to the HOT match $(2.4 \pm 1.0$ vs 3.0 $\pm 1.0 \mathrm{~g} / \mathrm{h} ; \mathrm{p}<0.05$ ).

\section{Match characteristics}

Total match duration did not differ between the HOT and HYD conditions. Match-play characteristics: number of points $(p=0.893)$, point duration $(p=0.786)$, between-point duration $(p=0.686)$ and effective playing time $(p=0.225)$ were also similar between conditions (table 1 ).

\section{Thermal, physiological and perceptual responses}

Core temperature increased significantly during each $10 \mathrm{~min}$ segment of effective play (figure $1 ; \mathrm{p}<0.05$ ); however, it was lower during the first $10 \mathrm{~min}$ in HYD compared with HOT $(\mathrm{p}<0.05)$. Similar core temperatures of $39.2 \pm 0.6^{\circ} \mathrm{C}(\mathrm{HYD})$ and $39.4 \pm 0.5^{\circ} \mathrm{C}(\mathrm{HOT})$ were reached at match-end. Skin temperature over the thigh was similarly elevated throughout both conditions, remaining unchanged over time. Heart rate was significantly lower throughout the HYD condition compared with HOT $(\mathrm{p}<0.001)$. Blood lactate levels were similar prematch $(1.9 \pm 0.6$ and $2.0 \pm 0.5)$ and postmatch $(2.6 \pm 1.2$ and 2.6 $\pm 0.6 \mathrm{mmol} / \mathrm{L})$ in the HYD and HOT conditions, respectively. Perceptual measures are presented in figure 2. Thermal comfort and RPE increased similarly over time in both conditions $(p<0.05)$. In contrast, thermal sensation was lower up to $7.5 \mathrm{~min}$ of effective play in the HYD compared with HOT condition $(\mathrm{p}<0.05)$.

Table 1 Number of points, point duration, between-point duration and effective playing percentage during $20 \mathrm{~min}$ of effective match-play tennis in HOT and HYD conditions

\begin{tabular}{llc}
\hline Characteristic & Condition & Match \\
\hline Number of points & HOT & $166.2 \pm 11.7$ \\
& HYD & $166.0 \pm 29.1$ \\
Point duration (s) & HOT & $7.4 \pm 0.6$ \\
& HYD & $7.6 \pm 1.2$ \\
Between-point duration (s) & HOT & $26.7 \pm 2.7$ \\
& HYD & $23.4 \pm 5.6$ \\
Effective play (\%) & HOT & $16.9 \pm 1.4$ \\
& HYD & $18.6 \pm 1.2$ \\
\hline
\end{tabular}

No significant difference between conditions, $p>0.05$. 


\section{Neuromuscular function}

A significant decrease in maximal voluntary $\mathrm{KE}$ and $\mathrm{PF}$ torque production was observed postmatch in both conditions relative to prematch (figure $3 ; \mathrm{p}<0.01$ ). This decrease was restored within $24 \mathrm{~h}$ in both muscle groups. VA in the $\mathrm{KE}$ was lower postmatch than prematch in both conditions $(\mathrm{p}<0.01)$, recovering within $24 \mathrm{~h}$. Conversely, VA in the PF was unaffected by the conditions or exercise. Peak twitch torque in the $\mathrm{KE}$ and $\mathrm{PF}$ was lower postmatch compared with prematch (table $2 ; \mathrm{p}<0.05$ ), increasing back to baseline levels at 24 and $48 \mathrm{~h}$.
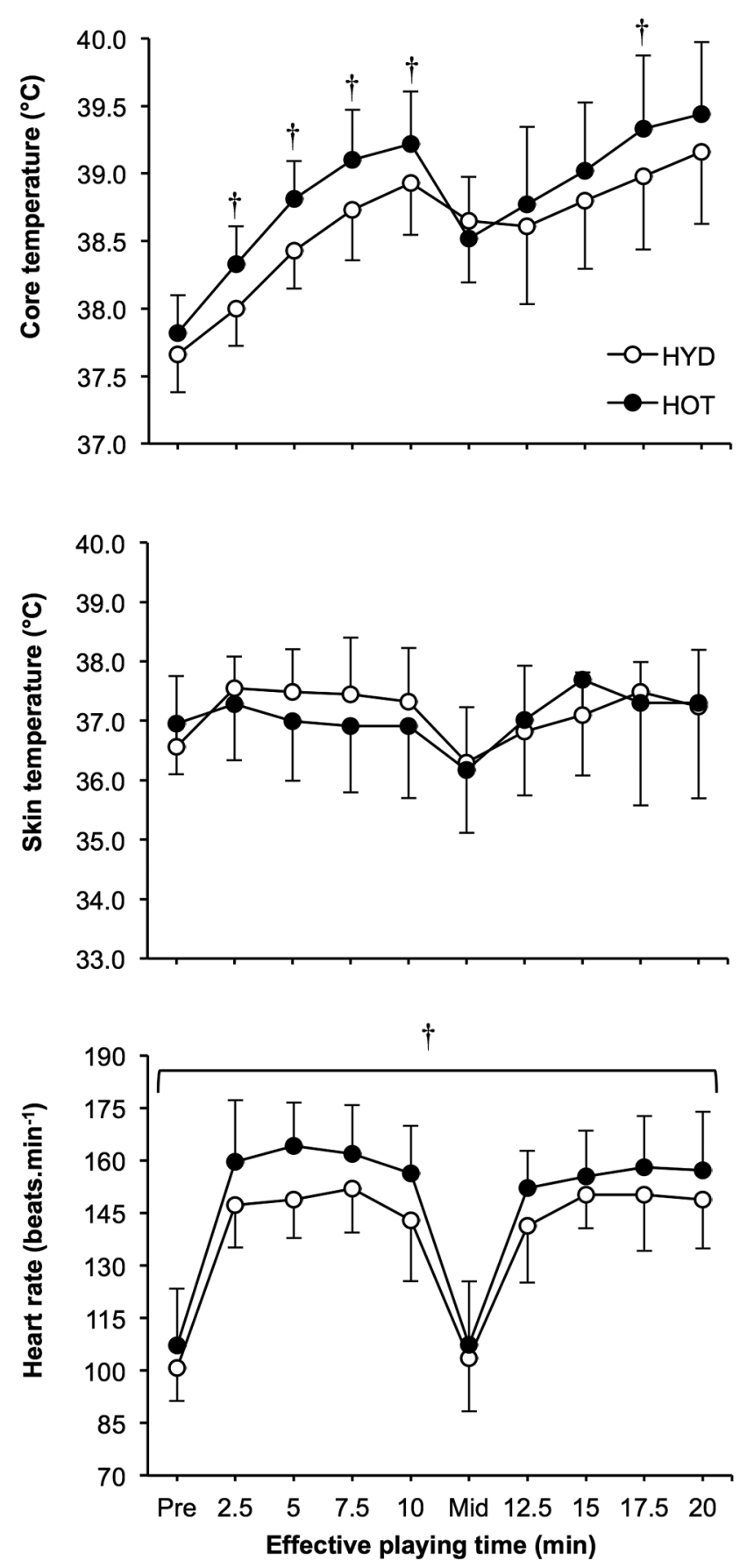

Figure 1 Heart rate, core and skin temperature during 20 min of effective match-play tennis in HOT and HYD conditions. +Significant difference between HOT and HYD, $p<0.05$.

\section{Physical performance}

Initial $15 \mathrm{~m}$ sprint time and total sprint time increased from prematch to postmatch in both conditions (table $3 ; \mathrm{p}<0.05$ ). These increases in time were restored 24 and $48 \mathrm{~h}$ after play in both conditions. There was no difference in the sprint decrement score between or within conditions. Performance during squat and countermovement jumps was also unaffected by the conditions or exercise.

\section{DISCUSSION}

The aim of this study was to determine whether an individualised hydration regimen-based on undertaking a tennis match
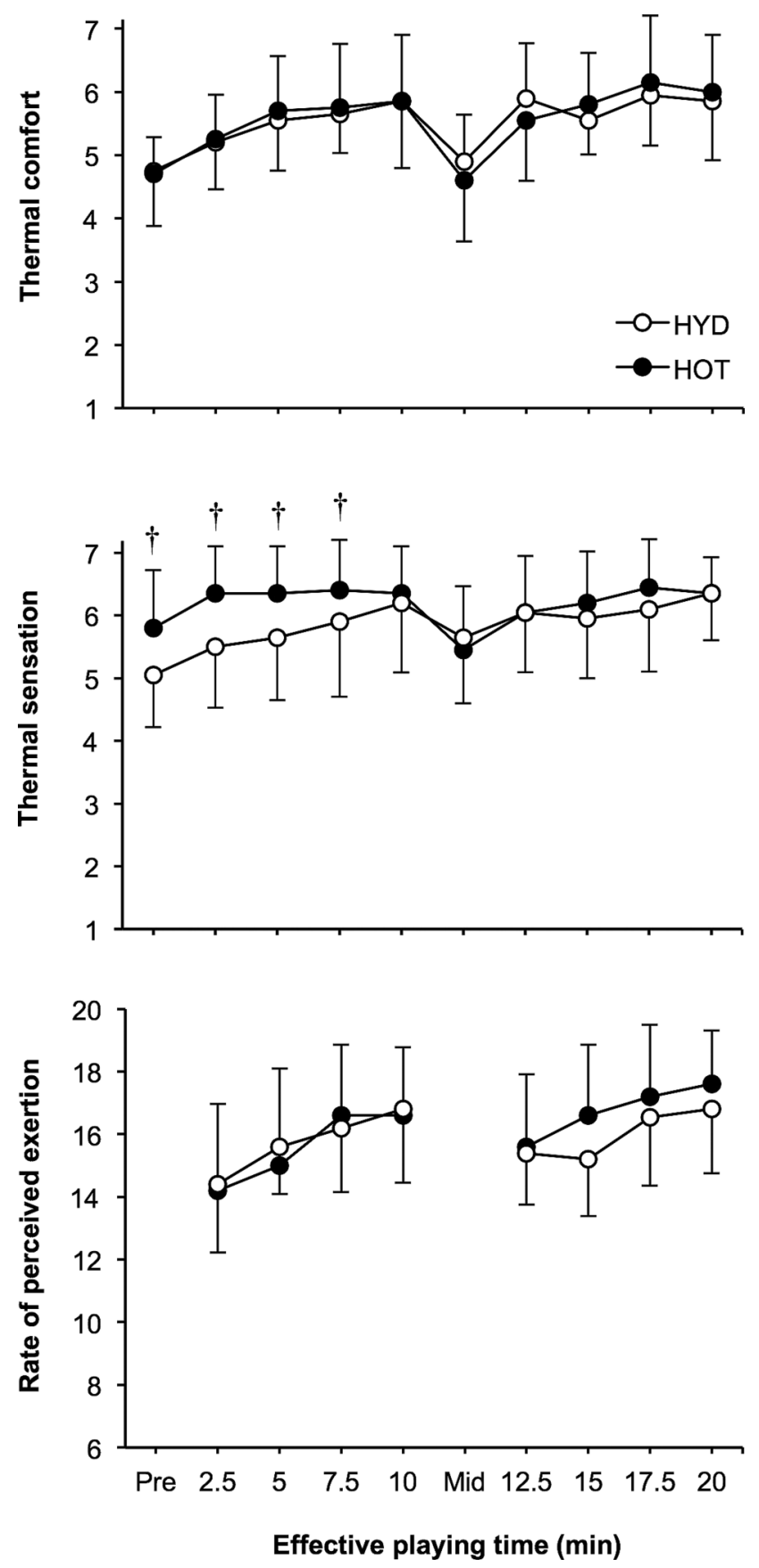

Figure 2 Thermal comfort, thermal sensation and rate of perceived exertion during 20 min of effective match-play tennis in HOT and HYD conditions. TSignificant difference between HOT and HYD, $p<0.05$. 

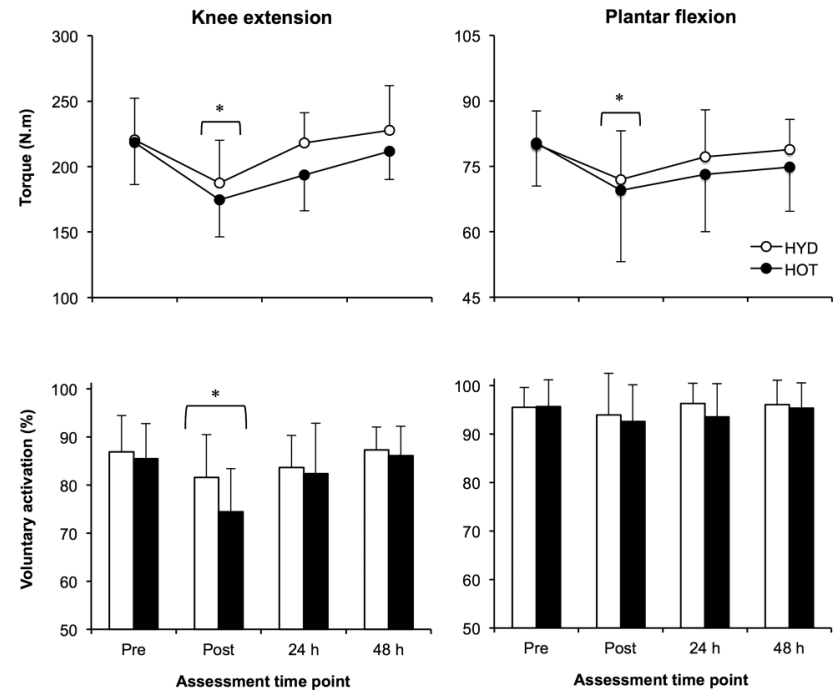

Figure 3 Knee extensor and plantar flexor torque production and voluntary activation prior to (Pre) and following (Post, $24 \mathrm{~h}$ and $48 \mathrm{~h}$ ) 20 min of effective match-play tennis in HOT and HYD conditions. * Significantly different from Pre, $p<0.05$.

( $\sim 2 \mathrm{~h})$ in a euhydrated state, along with minimising body mass losses and standardising $\mathrm{Na}^{+}$intake-reduced thermal, physiological and perceptual responses, and minimised alterations in neuromuscular function in the lower limbs as well as physical performance parameters during and following (24-48 h) play in the heat $\left(\sim 37^{\circ} \mathrm{C}\right)$. Our data provide evidence that (1) the hydration regimen contributed to attenuate thermal, perceptual and physiological strain, mainly during the first hour of play, while match-play characteristics evolved similarly; (2) acute postmatch strength losses in the KE and PF, along with impairments in $15 \mathrm{~m}$ sprint and repeated-sprint ability (ie, total sprint time and sprint decrement score), were not influenced by prematch hydration status when body mass losses remained $<1 \%$ and (3) complete recovery occurred within $24 \mathrm{~h}$, regardless of the hydration strategy employed.

\section{Hydration}

The main difference conferred by the hydration regimen in the current study was that it allowed for participants to undertake the HYD match in a euhydrated state, based on USG values and a slightly higher body mass, relative to the HOT condition. The USG values noted prior to the HOT match reinforce the notion that tennis players typically have poor prematch hydration habits. ${ }^{19}{ }^{20}$ Notwithstanding, changes in body mass during play were similar between the HOT and HYD conditions, owing to a

Table 2 Knee extensor (KE) and plantar flexor (PF) peak twitch torque prior to (Pre) and following (Post, $24 \mathrm{~h}$ and $48 \mathrm{~h}$ ) $20 \mathrm{~min}$ of effective match-play tennis in HOT and HYD conditions

\begin{tabular}{|c|c|c|c|c|}
\hline Condition & Pre & Post & $24 \mathrm{~h}$ & $48 \mathrm{~h}$ \\
\hline \multicolumn{5}{|c|}{ KE peak twitch torque ( $\mathrm{N} \mathrm{m}$ ) } \\
\hline HOT & $63.4 \pm 7.7$ & $58.0 \pm 8.8^{*}$ & $62.2 \pm 8.4$ & $64.8 \pm 8.7$ \\
\hline HYD & $63.8 \pm 8.9$ & $57.6 \pm 9.0^{*}$ & $60.7 \pm 8.3$ & $62.6 \pm 8.9$ \\
\hline \multicolumn{5}{|c|}{ PF peak twitch torque ( $\mathrm{N} \mathrm{m}$ ) } \\
\hline HOT & $15.9 \pm 3.9$ & $14.1 \pm 4.0^{*}$ & $14.5 \pm 3.3$ & $15.7 \pm 3.2$ \\
\hline HYD & $16.3 \pm 3.3$ & $13.8 \pm 2.8^{*}$ & $15.1 \pm 3.9$ & $15.7 \pm 4.0$ \\
\hline
\end{tabular}

similar fluid intake. Although participants were instructed to follow a hydration regimen in the HYD match only, they still consumed enough fluids to maintain their body mass loss $<1 \%$ in the HOT match. This is likely a reflection of the frequent breaks that occur during match-play tennis, which provide sufficient opportunities to ingest fluids and avoid excessive losses in body mass. Consequently, these losses rarely exceed $2 \%$, even during play in the heat. ${ }^{4} 1920{ }^{29-32}$ In certain cases, fluid consumption even surpasses that of sweat loss. ${ }^{33}$ Accordingly, individual sweat rates ranged from 1.0 to 2.2 (HOT) and 0.9 to $1.9 \mathrm{~L} / \mathrm{h}$ (HYD) in the current study, which is similar to mean values reported in the literature under warm to hot conditions. $^{12} 1931$

Despite similar sweat rates, sweat $\left[\mathrm{Na}^{+}\right]$was higher during the HOT match compared with HYD. Although sweat $\left[\mathrm{Na}^{+}\right]$in the current study was higher than previously reported during indoor $\left(17^{\circ} \mathrm{C}\right)^{33}$ and outdoor $\left(32^{\circ} \mathrm{C}\right)^{34}$ tennis matches, it was lower than in football players undertaking a heat-response test in $44^{\circ} \mathrm{C}$ conditions, ${ }^{35}$ and within the range typically observed under heat stress. ${ }^{5} 36$ Because of the higher concentration, total $\mathrm{Na}^{+}$losses (HOT range: 1.3-4.4g/h; HYD range: 1.1-4.2 g/h) were greater in the HOT than in the HYD match. This is an interesting finding, which may relate to several factors because sweat $\left[\mathrm{Na}^{+}\right]$can vary based on genetic predisposition, diet, sweat rate and heat acclimatisation state. ${ }^{5}$ It has also been shown that dehydration can increase sweat $\left[\mathrm{Na}^{+}\right]{ }^{37}$ In the current study, undertaking the HOT match in a hypohydrated state could have similarly contributed to increased sweat $\left[\mathrm{Na}^{+}\right]$, despite attaining a similar relative level of dehydration between matches.

Interestingly, excessive sweating with elevated $\left[\mathrm{Na}^{+}\right]$is associated with a greater incidence of muscle cramping in tennis and football players. ${ }^{34} 38$ To avoid muscle cramping, it is recommended to add $1500 \mathrm{mg} / \mathrm{L}$ of $\mathrm{Na}^{+}$to water or sports drinks consumed during play. ${ }^{34}$ Despite this recommendation, we chose to provide far less $\mathrm{Na}^{+}$during play, which resulted in no incidences of cramping. Likewise, when subjects began play in a slightly hypohydrated state and incurred minimal body mass losses (ie, HOT match), no muscle cramping occurred.

\section{Match-play responses and characteristics}

Undertaking the HYD match in a euhydrated state appears to have contributed to reduce physiological strain, as evidenced by a lower heart rate throughout play, relative to the HOT match (figure 1). The initial hydration level also seems to have reduced thermal strain, as demonstrated by a lower body core temperature during the first $10 \mathrm{~min}$ of effective play ( $\sim 60 \mathrm{~min}$ of total playing time) and a trend towards being reduced during the second $10 \mathrm{~min}$ segment of effective play, with a significantly lower temperature at after $\sim 100 \mathrm{~min}$ of total playing time in HYD. These responses may be attributed to the attenuating influence of euhydration on the rate of rise in core temperature. ${ }^{4910}$ Interestingly, the lower core temperature observed in the HYD match appears to have influenced thermal sensation, but not thermal comfort relative to the HOT match. Hence, participants felt equally hot, yet rated the playing environment as less hot or difficult to play in during HYD. Notwithstanding, the attenuation of thermal, physiological and perceptual strain reinforces the importance of undertaking play in a euhydrated state. This is supported by evidence for a carry-over effect on these measures of strain (eg, heart rate, core temperature and RPE) negatively impacting same-day repeated-bout exercise in the heat (eg, tournament play), despite adequate rehydration and core temperature returning to baseline between bouts. ${ }^{39} 40$ 
Table 3 Physical performance characteristics prior to (Pre) and following (Post, $24 \mathrm{~h}$ and $48 \mathrm{~h}$ ) 20 min of effective match-play tennis in HOT and HYD conditions

\begin{tabular}{|c|c|c|c|c|c|}
\hline Characteristic & Condition & Pre & Post & $24 \mathrm{~h}$ & $48 \mathrm{~h}$ \\
\hline $15 \mathrm{~m}$ sprint time (s) & $\begin{array}{l}\text { HOT } \\
\text { HYD }\end{array}$ & $\begin{array}{l}2.59 \pm 0.13 \\
2.54 \pm 0.14\end{array}$ & $\begin{array}{l}2.68 \pm 0.13^{*} \\
2.62 \pm 0.12^{*}\end{array}$ & $\begin{array}{l}2.60 \pm 0.16 \\
2.56 \pm 0.16\end{array}$ & $\begin{array}{l}2.58 \pm 0.15 \\
2.59 \pm 0.14\end{array}$ \\
\hline Total sprint time (s) & $\begin{array}{l}\text { HOT } \\
\text { HYD }\end{array}$ & $\begin{array}{l}7.93 \pm 0.41 \\
7.88 \pm 0.42\end{array}$ & $\begin{array}{l}8.15 \pm 0.39 * \\
8.09 \pm 0.38 *\end{array}$ & $\begin{array}{l}8.00 \pm 0.46 \\
7.89 \pm 0.40\end{array}$ & $\begin{array}{l}7.93 \pm 0.43 \\
7.98 \pm 0.40\end{array}$ \\
\hline Sprint decrement (\%) & $\begin{array}{l}\text { HOT } \\
\text { HYD }\end{array}$ & $\begin{array}{l}2.3 \pm 2.5 \\
3.3 \pm 1.8\end{array}$ & $\begin{array}{l}1.5 \pm 2.0 \\
2.8 \pm 2.4\end{array}$ & $\begin{array}{l}2.6 \pm 2.2 \\
2.7 \pm 2.0\end{array}$ & $\begin{array}{l}2.4 \pm 1.5 \\
2.8 \pm 0.5\end{array}$ \\
\hline Squat jump (cm) & $\begin{array}{l}\text { HOT } \\
\text { HYD }\end{array}$ & $\begin{array}{l}35.0 \pm 4.9 \\
35.1 \pm 5.1\end{array}$ & $\begin{array}{l}34.0 \pm 3.9 \\
35.5 \pm 4.6\end{array}$ & $\begin{array}{l}34.9 \pm 5.6 \\
34.6 \pm 5.7\end{array}$ & $\begin{array}{l}35.4 \pm 5.0 \\
35.8 \pm 5.5\end{array}$ \\
\hline Countermovement jump (cm) & $\begin{array}{l}\text { HOT } \\
\text { HYD }\end{array}$ & $\begin{array}{l}37.9 \pm 6.2 \\
37.7 \pm 6.5\end{array}$ & $\begin{array}{l}37.5 \pm 4.5 \\
37.4 \pm 4.5\end{array}$ & $\begin{array}{l}37.2 \pm 6.1 \\
37.2 \pm 5.5\end{array}$ & $\begin{array}{l}37.5 \pm 5.8 \\
38.1 \pm 5.3\end{array}$ \\
\hline
\end{tabular}

Ultimately, minimising the rise in core temperature and heart rate during match-play tennis in the heat is in the best interest of the player, as this will reduce the risk of heat illness and the potential for a carry-over effect on same-day matches.

The elevation in heart rate may also be associated with differences in relative exercise intensity between conditions. Indeed, increases in core temperature during prolonged heat-stress exercise are aligned with changes in relative intensity through the development of cardiovascular drift. ${ }^{41} 42$ Based on the core temperatures and heart rates attained during play in the current study, it may be speculated that relative exercise intensity was higher in the HOT compared with HYD match. However, RPE scores and blood lactate levels were similar across conditions, and within standard range. ${ }^{43-45}$ Thus, it is difficult to determine whether a difference in relative intensity occurred.

Interestingly, Carling ${ }^{46}$ suggested that the variability in physical performance during soccer matches is mediated by the inherent demands of the game. Similarly, match-play tennis is influenced by several factors such as playing style, playing surface, tactics, technical ability, score line and fitness, all of which can impact on the ability to self-regulate physical activity levels. ${ }^{45}$ In the current study, these factors may have contributed to influence metabolic heat production and the heart rate values attained, despite the opponent and climatic conditions remaining constant between matches. Changes in match characteristics (eg, point duration and between point duration) represent a further potential influence on cardiorespiratory load; however, no differences were noted between conditions (table 1). As such, it is unlikely that match characteristics were of significant influence on the changes noted in physiological, thermal and perceptual strain between conditions in the early stages of the matches. Nonetheless, to better understand the overall load imposed during match-play tennis, future studies should not only utilise match characteristics, but also measure on-court performance such as distance covered, number of displacements and distance per displacement, as well as stroke-specific measurements (eg, speed of groundstrokes and serve).

\section{Neuromuscular function}

Our data indicate that maximal voluntary torque production was equally impaired in the $\mathrm{KE}$ and $\mathrm{PF}$ following match-play tennis in HOT and HYD conditions (figure 3). In the KE, the decrement was associated with the development of central (ie, reduction in VA) and peripheral (ie, decrease in peak twitch torque) fatigue (table 2). Conversely, the decrease in PF torque was primarily associated with a significant reduction in twitch contractility, as VA levels remained elevated during all contractions. The discrepancy in central fatigue development between muscle groups has been observed following running and cycling and suggests that the maximal VA is more easily attained and maintained in the $\mathrm{PF},{ }^{47-49}$ likely due to muscle fibre composition. ${ }^{5051}$ Regardless, the progressive development of fatigue in both muscle groups has the potential to considerably impact performance through reductions in the efficiency of on-court movements, as well as stroke proficiency. ${ }^{1}{ }^{5}$ However, it appears that these impairments may represent acute adjustments, as lower limb strength was recovered within $24 \mathrm{~h}$.

Although it may be speculated that the initial hypohydrated state ( $1 \%$ lower body mass) in which participants undertook the HOT match could have negatively influenced prematch and postmatch torque production capacity, it has been shown that moderate dehydration ( $2.5 \%$ body mass deficit), isolated from acute exercise-heat stress, does not impact on strength during a single MVC or enhance fatigability during multiple contractions. ${ }^{51}$ Hence, the reduction in strength observed postmatch in both conditions appears to reflect fatigue mainly at the skeletal muscle level. This observation is supported by previous findings of strength losses in the $\mathrm{KE}$ and $\mathrm{PF}$ during brief and sustained MVCs performed immediately following prolonged (ie, cycling) and intermittent (ie, tennis) exercise, irrespective of core temperature. ${ }^{53-58}$

\section{Physical performance}

The ability to maintain explosiveness of movements is a key factor for success in tennis. ${ }^{56}$ In the current study, squat and countermovement jumps were unaffected by playing in HOT or HYD conditions (table 3). These jumps reflect the explosive power of the lower limbs and indicate that in single one-off efforts, explosiveness may be maintained, despite impairments in neuromuscular function. This may stem from the positive dose/response relationship that exists between increases in muscle temperature and muscle power, which suggests that highvelocity movements (eg, brief explosive jumping) are more temperature dependent than low-velocity movements (eg, sustained cycling at a low cadence). ${ }^{59}$ The maintenance of brief explosive movements may also result from a fatigue-related compensatory neuromuscular reorganisation of the movement strategy, especially in the countermovement jump, which has previously been reported to remain unchanged after match-play. ${ }_{5} 50$

In contrast, a reduction in body mass of $\sim 2.7 \%$ is known to negatively affect 5 and $10 \mathrm{~m}$ sprint times after $120 \mathrm{~min}$ of match-play tennis in a warm environment $\left(\sim 31^{\circ} \mathrm{C}\right) .{ }^{61}$ Our data indicate that, despite only modest dehydration $(<1 \%), 15 \mathrm{~m}$ 
sprint and total sprint times were reduced postmatch relative to prematch in both conditions, whereas the sprint decrement score was maintained (albeit slightly reduced). The similarity in sprint decrement score and the reduction in initial/total sprinting times are indicative of a fast-developing fatigue during the repeated maximal efforts, resulting from match-play, rather than dehydration. This fatigue, in association with the reduction in sprint speed, has previously been suggested to reflect neuromechanical adjustments (ie, impaired musculoskeletal stiffness regulation via reductions in the tolerance of impact forces or stretch load). ${ }^{62}$ Taken together with the strength losses experienced by lower limb muscles (figure 3), the progressive decrease in running speed when maximal efforts are repeated after match-play tennis may result in reduced stroke effectiveness. ${ }^{44}$ Given the relatively rapid recovery of these parameters (within $24 \mathrm{~h}$ ), emphasis should be placed on strategies that attenuate the development of fatigue during play through specific sprint training protocols (eg, repeated efforts at or above match speed).

\section{Limitations}

Given the need to calculate individual sweat rates following the HOT match, it was not possible to counterbalance the HOT and HYD trials. Although there may have been a learning effect in the battery of assessments performed, participants were thoroughly familiarised with all tests. As such, a learning effect was unlikely to occur. Another potential limitation is the development of heat acclimatisation occurring from the HOT to the HYD match. Indeed, it is known that decreases in heart rate, perceived exertion and renal $\left[\mathrm{Na}^{+}\right]$, along with plasma volume expansion, occur in 3-6 days of acclimatisation. ${ }^{63}$ In contrast, decreases in resting core temperature and sweat $\left[\mathrm{Na}^{+}\right]$, as well as increases in sweat rate have been suggested to develop from the fifth day of acclimatisation onward. ${ }^{63}$ Thus, while there may have been an acclimatisation effect on measures of heart rate and perceived exertion, our findings of differences in core temperature and sweat $\left[\mathrm{Na}^{+}\right]$appear to have been the result of the hydration regimen, more specifically undertaking the HYD match in a euhydrated state, especially considering that eight players had $72 \mathrm{~h}$ between matches and only two had $144 \mathrm{~h}$.

\section{CONCLUSION}

This study provides the first direct comparison of match-play tennis in the heat of high-level players adopting their typical hydration habits versus implementing an individualised hydration regimen. We have demonstrated that an individualised hydration regimen reduces thermal (ie, core temperature), perceptual (ie, thermal sensation) and physiological (heart rate) strain, mainly during the first hour of play, relative to ad libitum fluid consumption. These reductions appear to have been conferred by undertaking the hydration match in a euhydrated state, optimising sodium intake and minimising body mass losses; however, the development of adaptations related to heat acclimatisation on these reductions cannot be overlooked. Conversely, the hydration regimen had no impact on lower limb strength losses, alterations in physical performance and matchplay characteristics, as these were similarly affected by the development of fatigue during play. In addition, body mass losses remained $<1 \%$ during play in HYD and HOT, and strength and physical performance parameters were restored within $24 \mathrm{~h}$ of match completion.

\section{What are the new findings?}

- Following an individualised hydration regimen prior to and during match-play tennis $(\sim 2 \mathrm{~h})$ in the heat $\left(\sim 37^{\circ} \mathrm{C}\right)$ attenuates thermal, perceptual and physiological strain, relative to playing in the same environmental conditions, but consuming fluids ad libitum before and throughout play.

- The reductions in strain are mainly observed in the first hour of play and appear to stem from undertaking the matches in a euhydrated state, optimising sodium intake and preventing large decrements in body mass.

- Lower limb strength, physical performance and match-play characteristics are similarly influenced by the development of fatigue during play in the heat, irrespective of prematch hydration state, provided that body mass losses remain $<1 \%$ during play.

\section{How might it impact on clinical practice?}

- Individual player habits regarding precompetition hydration should be monitored to ensure that they undertake play in a euhydrated state, especially in the heat, in order to avoid a potential carry-over effect negatively impacting same-day performance.

- General recommendations about precompetition hydration should be established not only for the hours preceding a match, but also for $24 \mathrm{~h}$, in order to ensure proper hydration.

Acknowledgements The authors thank all the participants for their participation in this study. Also thanks to the coaches, Tim Colijn and Samuel Rota, for conducting the practises during the days between matches. Finally, the authors thank Mr Stephen Gurr for his input regarding nutrition and in particular his help in developing the hydration regimen.

Contributors JDP, OG, SR, CPH, WLK and RJC contributed to the development of the project. JDP, OG, SR and RJC collected and analysed the data. JDP, OG, SR, $\mathrm{CPH}$, WLK and RJC had intellectual input in drafting the manuscript. All authors gave final approval for submitting the manuscript.

Funding This project was funded by the Aspire Zone Foundation Research Grant. Competing interests None.

Ethics approval The study was approved by the Shafallah Medical Genetics Center Ethical Research Committee and conformed to the current Declaration of Helsinki guidelines.

Provenance and peer review Not commissioned; externally peer reviewed.

Open Access This is an Open Access article distributed in accordance with the Creative Commons Attribution Non Commercial (CC BY-NC 3.0) license, which permits others to distribute, remix, adapt, build upon this work non-commercially, and license their derivative works on different terms, provided the original work is properly cited and the use is non-commercial. See: http://creativecommons.org/ licenses/by-nc/3.0/

\section{REFERENCES}

1 Hornery DJ, Farrow D, Mujika I, et al. Fatigue in tennis: mechanisms of fatigue and effect on performance. Sports Med 2007;37:199-212.

2 Périard JD, Girard 0, Racinais S. Neuromuscular adjustments of the knee extensors and plantar flexors following match-play tennis in the heat. Br J Sports Med 2014;48:i45-51. 
3 Périard JD, Racinais S, Knez WL, et al. Thermal, physiological and perceptual strain mediate alterations in match-play tennis under heat stress. Br J Sports Med 2014;48:i32-8.

4 Morante SM, Brotherhood JR. Autonomic and behavioural thermoregulation in tennis. Br J Sports Med 2008;42:679-85.

5 Sawka MN, Burke LM, Eichner ER, et al. American College of Sports Medicine position stand: exercise and fluid replacement. Med Sci Sports Exerc 2007;39:377-90.

6 Kovacs MS. Hydration and temperature in tennis - a practical review. J Sports Sci Med 2006:5:1-9.

7 Kovacs MS. A review of fluid and hydration in competitive tennis. Int I Sports Physiol Perform 2008:3:413-23.

8 Maughan RJ, Shirreffs SM. Dehydration and rehydration in competative sport. Scand J Med Sci Sports 2010:20:40-7.

9 Cheuvront SN, Carter RC, Sawka MN. Fluid balance and endurance exercise performance. Curr Sports Med Rep 2003:2:202-8.

10 Sawka MN, Latzka WA, Matott RP, et al. Hydration effects on temperature regulation. Int J Sports Med 1998;19:S108-10.

11 Bergeron MF, Armstrong LE, Maresh CM. Fluid and electrolyte losses during tennis in the heat. Clin Sports Med 1995;14:23-32.

12 Bergeron MF, Maresh CM, Armstrong LE, et al. Fluid-electrolyte balance associated with tennis match play in a hot environment. Int J Sport Nutr 1995;5:180-93.

13 Goulet EDB. Effect of exercise-induced dehydration on time-trial exercise performance: a meta-analysis. Br J Sports Med 2011;45:1149-56.

14 Sawka MN, Noakes TD. Does dehydration impair exercise performance? Med SCi Sports Exerc 2007;39:1209-17.

15 Armstrong LE, Hubbard RW, Szlyk PC, et al. Voluntary dehydration and electrolyte losses during prolonged exercise in the heat. Aviat Space Environ Med 1985;56:765-70.

16 Greenleaf JE. Problem: thirst, drinking behavior, and involuntary dehydration. Med Sci Sports Exerc 1992;24:645-56.

17 Adolph EF. Physiology of man in the desert. New York: Interscience, 1947.

18 Coyle EF, Montain SJ. Benefits of fluid replacement with carbohydrate during exercise. Med Sci Sports Exerc 1992:24:S324-30.

19 Bergeron MF, Waller JL, Marinik EL. Voluntary fluid intake and core temperature responses in adolescent tennis players: sports beverage versus water. $\mathrm{Br} / \mathrm{Sports}$ Med 2006:40:406-10.

20 Hornery DJ, Farrow D, Mujika I, et al. An integrated physiological and performance profile of professional tennis. Br J Sports Med 2007:41:531-6.

21 Girard O, Christian RJ, Racinais S, et al. Heat stress does not exacerbate tennisinduced alterations in physical performance. Br J Sports Med 2014;48:i39-44.

22 Maughan R. Fluid and carbohydrate intake during exercise. In: Burke LM, Deakin V. eds. Clinical sports nutrition. North Ryde: McGraw-Hill, 2010:330-57.

23 International Tennis Federation. International Tennis Federation Rules of Tennis 2012. http://www.itftennis.com. 2012. http://www.itftennis.com/media/107013/ 107013.pdf (accessed 9 Jul 2013).

24 Bedford T. The warmth factor in comfort at work: a physiological study of heating and ventilation. Industrial Health Research Board 1936; Report No. 76.

25 ASHRAE. Thermal comfort conditions. New York: ASHRAE standard, 1966

26 Borg GA. Psychophysical bases of perceived exertion. Med Sci Sports Exerc 1982;14:377-81

27 Merton PA. Voluntary strength and fatigue. J Physiol 1954;123:553-64.

28 Lehance C, Croisier JL, Bury T. Validation du système Optojump en tant qu" outil d"évaluation de la force-vitesse (puissance) des membres inférieurs. Sci Sports 2005;20:131-5.

29 Tippet ML, Stofan JR, Lacambra M, et al. Core temperature and sweat responses in professional women's tennis players during tournament play in the heat. J Ath Train 2011;46:55

30 Bergeron MF, McLeod KS, Coyle JF. Core body temperature during competition in the heat: national boys' $14 \mathrm{~s}$ junior tennis championships. Br J Sports Med 2007:41:779-83.

31 Morante SM, Brotherhood JR. Air temperature and physiological and subjective responses during competitive singles tennis. Br J Sports Med 2007:41:773-8.

32 McCarthy PR, Thorpe RD, Williams C. Body fluid loss during competitive tennis match-play. In: Lees A, Maynard I, Hughes M, et al., eds. Science and racket sports II. London: E \& FN Spon, 1998:52-5.

33 Lott MJ, Galloway SD. Fluid balance and sodium losses during indoor tennis match play. Int J Sport Nutr Exerc Metab 2011;21:492-500.

34 Bergeron MF. Heat cramps - fluid and electrolyte challenges during tennis in the heat. J Sci Med Sport 2003:6:19-27.
35 Racinais S, Mohr M, Buchheit M, et al. Individual responses to short-term heat acclimatisation as predictors of football performance in a hot, dry environment. $\mathrm{Br} J$ Sports Med 2012:46:810-15.

36 Sawka MN, Montain SJ. Fluid and electrolyte supplementation for exercise heat stress. Am J Clin Nutr 2000:72:564S-72S.

37 Morgan RM, Patterson MJ, Nimmo MA. Acute effects of dehydration on sweat composition in men during prolonged exercise in the heat. Acta Physio/ Scand 2004; 182:37-43.

38 Horswill CA, Stofan JR, Lacambra M, et al. Sodium balance during U.S. footbal training in the heat: cramp-prone vs. reference players. Int J Sports Med 2009;30:789-94.

39 Bergeron MF, Laird MD, Marinik EL, et al. Repeated-bout exercise in the heat in young athletes: physiological strain and perceptual responses. J App/ Physiol 2009:106:476-85

40 Sawka MN, Knowlton RG, Critz JB. Thermal and circulatory responses to repeated bouts of prolonged running. Med Sci Sports 1979:11:177-80.

41 Rowell LB. Human circulation: regulation during physical stress. New York: Oxford University Press, 1986.

42 Arngrimsson SA, Stewart DJ, Borrani F, et al. Relation of heart rate to percent VO2peak during submaximal exercise in the heat. J App/ Physiol 2003;94:1162-8.

43 Smekal G, von Duvillard SP, Rihacek C, et al. A physiological profile of tennis match play. Med Sci Sports Exerc 2001;33:999-1005

44 Ferrauti $\mathrm{A}$, Bergeron MF, Pluim BM, et al. Physiological responses in tennis and running with similar oxygen uptake. Eur J Appl Physiol 2001;85:27-33.

45 Fernandez J, Mendez-Villanueva A, Pluim BM. Intensity of tennis match play. $\mathrm{Br} \mathrm{J}$ Sports Med 2006;40:387-91

46 Carling C. Interpreting physical performance in professional soccer match-play: should we be more pragmatic in our approach? Sports Med 2013;43:655-63.

47 Racinais S, Girard 0. Neuromuscular failure is unlikely to explain the early exercise cessation in hot ambient conditions. Psychophysiology 2012;49:853-65.

48 Martin V, Kerherve H, Messonnier LA, et al. Central and peripheral contributions to neuromuscular fatigue induced by a $24-\mathrm{h}$ treadmill run. J Appl Physiol 2010;108:1224-33.

49 Millet GY, Tomazin K, Vergès $S$, et al. Neuromuscular consequences of an extreme mountain ultra-marathon. PLOS ONE 2011;22:e17059.

50 Behm DG, Whittle J, Button D, et al. Intermuscle differences in activation. Muscle Nerve 2002;25:236-43.

51 Henneman E, Clamann HP, Gillies JD, et al. Rank order of motoneurons within a pool: law of combination. J Neurophysiol 1974;37:1338-49.

52 Girard O, Millet GP. Neuromuscular fatigue in racquet sports. Neurol Clin 2008;26:181-94

53 Périard JD, Tammam AH, Thompson MW. Skeletal muscle strength and endurance are maintained during moderate dehydration. Int J Sports Med 2012 33:607-12.

54 Girard O, Racinais S, Micallef JP, et al. Spinal modulations accompany peripheral fatigue during prolonged tennis playing. Scand J Med Sci Sports 2011;21:455-64

55 Girard O, Lattier G, Micallef JP, et al. Changes in exercise characteristics, maximal voluntary contraction, and explosive strength during prolonged tennis playing. $\mathrm{Br} J$ Sports Med 2006;40:521-6.

56 Girard O, Lattier G, Maffiuletti NA, et al. Neuromuscular fatigue during a prolonged intermittent exercise: application to tennis. J Electromyogr Kinesio/ 2008;18:1038-46.

57 Périard JD, Cramer MN, Chapman PG, et al. Neuromuscular function following prolonged intense self-paced exercise in hot climatic conditions. Eur J App/ Physiol 2011:111:1561-9.

58 Nybo L, Nielsen B. Hyperthermia and central fatigue during prolonged exercise in humans. J App/ Physiol 2001:91:1055-60.

59 Racinais S, Oksa J. Temperature and neuromuscular function. Scand J Med Sci Sports 2010:20:1-18.

60 Ojala T, Häkkinen K. Effects of the tennis tournament on players' physical performance, hormonal responses, muscle damage and recovery. J Sports Sci Med 2013;12:240-8.

61 Magal M, Webster MJ, Sistrunk LE, et al. Comparison of glycerol and water hydration regimens on tennis-related performance. Med Sci Sports Exerc 2003;35:150-6.

62 Girard O, Micallef J-P, Millet GP. Changes in spring-mass mode characteristics during repeated running sprints. Eur J Appl Physiol 2011;111: 125-34.

63 Armstrong LE, Maresh CM. The induction and decay of heat acclimatisation in trained athletes. Sports Med 1991;12:302-12.

64 Garrett AT, Rehrer NJ, Patterson MJ. Induction and decay of short-term heat acclimation in moderately and highly trained athletes. Sports Med 2011:41: 757-71. 